\title{
(6) \\ Research led by participants: a new social contract for a new kind of research
} OPEN ACCESS

\author{
Effy Vayena, ${ }^{1}$ Roger Brownsword, ${ }^{2}$ Sarah Jane Edwards, ${ }^{3}$ Bastian Greshake, ${ }^{4}$ \\ Jeffrey P Kahn, ${ }^{5}$ Navjoyt Ladher, ${ }^{6}$ Jonathan Montgomery, ${ }^{7}$ Daniel O'Connor, ${ }^{8}$ \\ Onora O'Neill, ${ }^{9}$ Martin P Richards, ${ }^{10}$ Annette Rid, ${ }^{11}$ Mark Sheehan, ${ }^{12}$ \\ Paul Wicks, ${ }^{13}$ John Tasioulas ${ }^{14}$
}

For numbered affiliations see end of article.

Correspondence to Dr Effy Vayena, Institute of Biomedical Ethics, University of Zurich, Pestalozzistrasse 24, Zurich 8032, Switzerland; vayena@ethik.uzh.ch

Received 2 January 2015 Accepted 18 February 2015 Published Online First 30 March 2015

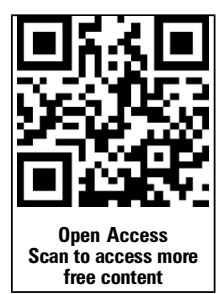

\section{SLinked}

http://dx.doi.org/10.1136 medethics-2015-102704

- http://dx.doi.org/10.1136/ medethics-2015-102731

- http://dx.doi.org/10.1136/ medethics-2015-103003

\section{CrossMark}

To cite: Vayena $E$

Brownsword R, Edwards SJ,

et al. J Med Ethics

2016:42:216-219.

\section{ABSTRACT}

In recent years, there have been prominent calls for a new social contract that accords a more central role to citizens in health research. Typically, this has been understood as citizens and patients having a greater voice and role within the standard research enterprise. Beyond this, however, it is important that the renegotiated contract specifically addresses the oversight of a new, path-breaking approach to health research: participant-led research. In light of the momentum behind participant-led research and its potential to advance health knowledge by challenging and complementing traditional research, it is vital for all stakeholders to work together in securing the conditions that will enable it to flourish.

It is increasingly commonplace to hear calls for patients to have a greater voice in medicine and to work in partnership with clinicians and researchers in improving healthcare. ${ }^{1-3}$ In health research, funding bodies and academic institutions actively undertake patient and public involvement programmes to ensure that studies adequately reflect the perspectives and input of patients and citizens. Despite measures to engage patients, however, their role still remains limited within standard research. These limitations have motivated a new approach to research in which patients and citizens take matters into their own hands in designing and conducting research activities. We have termed this new phenomenon participant-led research (PLR) and we contend that it needs to be governed by a new social contract.

\section{WHAT IS PLR?}

As in standard research, PLR is an activity that characteristically aims at the socially valued goal of producing generalisable health knowledge. However, it is distinctive in being initiated and conducted by the participants themselves, often using the tools of online social media. Many of the participants in PLR are patients suffering from the condition that is the subject of their research. However, PLR also includes participants who are not patients, but rather individuals interested in acquiring health information, whether about themselves or more generally. The PLR label applies to a very heterogeneous range of research activities. Often, they cannot be sharply distinguished from standard research, partly because of the tendency of some PLR projects to evolve over time and become entangled with standard research activity. ${ }^{4}$
Several examples illustrate the diversity of activity in the growing field of PLR. Perhaps the most well known case is the amyotrophic lateral sclerosis (ALS) lithium study carried out on the online platform PatientsLikeMe. It was initiated by two patients with advanced-stage ALS from Brazil and the USA, both of whom died prior to the completion of the study. ${ }^{5}$ One hundred and forty-nine patients with ALS on the platform took lithium in order to test the findings of a small earlier study into its effects on disease progression and symptom alleviation. The PatientsLikeMe ALS study, which was completed over 8 months, was eventually published in Nature Biotechnology. Its finding that lithium had no effect was subsequently confirmed by standard clinical trials. ${ }^{6}$

A rather different example, profiled recently in the Wall Street Journal, is the research experiment conducted by parents of children suffering from the extremely rare lipid storage disease, Niemann-Pick Type C. ${ }^{7}$ In their quest for a cure, the parents engaged in extensive negotiations with the Food and Drug Administration for permission to administer cyclodextrin to their children, first intravenously, and then eventually directly into the spinal fluid. These activities led to a phase 1 clinical trial of cyclodextrin. ${ }^{8}$ Other examples of PLR activity include online platforms on which individuals can upload their genetic data, usually acquired via direct-to-consumer genomic companies, for the purpose of initiating research. ${ }^{9} 10$

PLR activity is likely to become increasingly common and diverse. Along with the call for greater patient engagement in healthcare and participantcentric initiatives for managing self-collected data, various forms of PLR will aspire to become a recognised part of the process of health knowledge production. However, given the distinctive nature of these activities, including their differences from standard research, it is not obvious that they should be governed by the existing social contract for health research. This contract, which sets out norms and mechanisms for conducting and recognising research, including oversight and accountability procedures, was devised exclusively with standard research in mind. We therefore need to agree on a new social contract that will enable us to harness the great potential of PLR while avoiding the major pitfalls that lie in its path.

\section{WHAT ARE THE POTENTIAL BENEFITS AND PITFALLS?}

PLR is potentially valuable as a source of generalisable health knowledge that benefits participants 
and the wider society. Moreover, through PLR, this knowledge can be generated in ways that realise the important value of participation in scientific research, something to which there is a human right under the broader rubric of participation in science and culture. ${ }^{11} 12$ It promises to be a vital supplement to standard research: it can focus on conditions that are neglected by standard research, such as rare diseases or side effects, and can draw on a broader range of data and deliver outcomes more rapidly. ${ }^{13}$ It can also be a way of realising valuable forms of social interaction and support in cases where members of a community conduct PLR together, for example, patients suffering from the same illness.

Like any mode of scientific research with human participants, however, PLR may involve the risk of harm to participants or others, including relatives. Beyond the issue of harm, research activity may imperil societal values such as dignity and justice. Certain characteristic features of PLR can exacerbate these concerns: for example, self-experimentation may lead participants to run excessive risks, and the existence of a community may provide a setting that facilitates undue peer pressure and exploitation. In addition to these concerns, PLR may face special obstacles in meeting epistemic standards required of scientific research, including problems of bias and distortion arising from the use of self-reported and self-collected data. ${ }^{14} 15$

\section{WHY IS A NEW SOCIAL CONTRACT NECESSARY?}

It is important to negotiate the terms on which PLR is socially recognised and enabled to flourish, keeping the potential benefits and pitfalls in mind. Of course, society has a legitimate general interest in regulating the permissibility of actions that may harm those engaged in them or impact negatively on third parties and publicly funded health services. However, our specific focus here is not on the permissibility of PLR. We assume that PLR activity would be generally permissible within a just legal framework. Instead, our focus is on the separate question of the conditions under which PLR should be socially recognised as a valuable means of contributing to generalisable health knowledge. Such recognition carries with it further implications. For example, it is a basis for providing material support for PLR, incorporating its outputs into the body of scientific knowledge and translating those outputs into practice.

The existing social contract does not explicitly recognise PLR as an authentic mode of research, an omission that may have various unwelcome consequences. For example, it could undercut the motivation to engage in PLR activity, sending the erroneous message that it is an eccentric and insignificant activity. It could also create obstacles to the dissemination and use of generalisable knowledge acquired through PLR. For example, journal editors may face the quandary of whether to publish seemingly important research that has not gone through standard research oversight procedures, for example, ethics review by a Research Ethics Committee (REC) or an Institutional Review Board (IRB).

Clinicians may face similar problems, such as whether to make use of PLR findings, even if they have been published, or how best to advise patients who are contemplating the prospect of engaging in such research. More generally, PLR will present health practitioners with patients who have a novel profile. In addition to having scientific understanding of their condition, they will also have the experience of taking responsibility for research design, oversight and implementation. This enhanced status is likely to have transformative implications for the patient-practitioner relationship. ${ }^{16}$
In light of this situation, we propose that the new social contract on health research should set out relevant standards that those involved in PLR must satisfy if their activities are to be socially recognised as research. In turn, the wider society, including scientific journals, funding bodies and healthcare professionals, would have corresponding responsibilities to recognise and facilitate PLR that meets these standards.

\section{SOCIAL RECOGNITION OF PLR AS RESEARCH: A MATTER OF MUTUAL RESPONSIBILITY}

The rationale for subjecting health research to oversight, scientific and ethical, is to facilitate its ability to produce generalisable health knowledge that can be properly recognised and used by the participants and society. Such oversight provides assurance of the scientific quality of research outcomes, and the ethical acceptability of the ways in which they were achieved. The same quality assurance requirements apply in no less measure to PLR if it is to be recognised as genuine research.

In standard research the means of securing these requirements involve formal scientific and ethical review. In relation to PLR, by contrast, such mechanisms tend to be neither in operation, nor easily accessible. A crucial question is whether PLR should also be subjected to identical formal oversight mechanisms. The worry is that these mechanisms may needlessly deter or burden those engaged in valuable forms of PLR due to the cost, delay and difficulty of undergoing formal review.

To strengthen the ability of PLR to meet the conditions for social recognition, we should be prepared to accept alternative mechanisms of oversight that are adapted to the distinctive character of PLR. ${ }^{17}$ Appropriate mechanisms should be identified in a new social contract on PLR that outlines the reciprocal responsibilities of those engaged in PLR activities and of others in the societies hosting these activities. The social contract would facilitate PLR activity by providing a publicly accessible set of standards for its oversight, operating as a focal point that coordinates the activities of diverse stakeholders in relation to such research, for example, PLR practitioners, journal editors, funding bodies, health professionals, regulators, etc.

\section{CONSTRUCTING THE TERMS OF THE NEW SOCIAL CONTRACT}

In shaping the terms of the new social contract that enables PLR to be recognised as a legitimate, reliable and responsible research activity, the points listed below should be taken into account. These considerations are offered, in the first instance, as governing the 'soft regulation' of PLR, by means of socially acknowledged responsibilities, rather than legally enforceable measures. It follows that an effective social contract will require a real sense of ownership on the part of relevant stakeholders, especially those engaged in PLR activities. This includes their full participation in the negotiation of the new social contract.

1. Uniform ethical and scientific standards apply throughout. PLR should meet the same high ethical and scientific standards expected of standard research. PLR should not be relegated per se to the status of 'second-class' research, either ethically or scientifically. Equally, however, standards should not be relaxed to allow poor quality research to be passed off as first-class research. ${ }^{18}$

2. Uniform standards may be secured through diverse mechanisms of oversight. Although ethical and scientific standards apply uniformly across all types of research, the most appropriate means for securing them may vary from one kind of research to another. We should not assume that a one-size-fits-all mechanism of oversight is best. Instead, we 
must explore various approaches which take into account the distinctive nature of the research in question. Moreover, given the heterogeneous character of PLR activity, different oversight mechanisms may apply to different kinds of research within that general category. ${ }^{17}$

3. Features of PLR which might justify alternative mechanisms of oversight. Among the various ways in which PLR tends to contrast with standard research are the following: PLR is usually pursued outside of institutional frameworks and without official endorsement or support; it is often a less formally structured peer-to-peer activity, but not one in which power relations among participants are absent; participants often have a direct health interest in the outcome of research; the research conducted may address issues outside of the scientific mainstream, or may challenge mainstream approaches; the research is often not motivated by commercial profit or career advancement; it is more likely to involve forms of self-experimentation; it may be conducted in a more 'open' or 'transparent' manner, especially when enabled by online media; and so on. These and other differentiating features do not have uniform implications for the oversight of PLR, and such implications need to be balanced in devising suitable oversight mechanisms. ${ }^{19}$

4. Procedural and substantive dimensions of oversight. In adapting oversight mechanisms to the distinctive nature of PLR, we should distinguish their procedural and substantive dimensions. Procedural questions concern the means through which oversight is to be achieved, for example, through traditional REC or IRB, a committee of participants, crowd-sourcing, etc. Substantive questions concern the considerations that those operating the procedures should bring to bear in judging the acceptability of a research proposal.

5. Procedural adaptation. We should not simply assume that the procedure through which oversight is conducted must involve standard research ethics review (REC/IRB). The automatic and wholesale imposition of this mode of review, with its financial burdens and delay, threatens to discourage or stifle valuable forms of PLR activity. Instead, it is imperative to explore other procedures of oversight, and also to entertain the possibility that different procedures are applicable to different kinds of activity within the PLR rubric. Among the alternatives worth exploring in this way is ethical oversight by means of crowd-sourcing or swarm-sourcing (a more filtered version of the former).

6. Substantive adaptation. Even though the ultimate standards of oversight are uniform across all forms of research, certain considerations may assume a special prominence in PLR. While risk to participants remains the primary ethical concern, PLR's distinctive nature may demand a special focus on matters such as the interests of third parties (including children of participants involved in research) or wider societal values, data protection concerns arising out of the extensive use of online media, and the corrosion of informed consent through peer pressure and group dynamics, among others. ${ }^{20}$

7. Responsibilities on participants and society. Practitioners of PLR have a responsibility to meet relevant ethical and scientific standards as a condition of their research being socially recognised. Correspondingly, society has an obligation to enable participants in PLR to discharge their responsibilities, and a further obligation to accord PLR its due recognition as research when the relevant ethical and scientific standards are met.

8. Forms of social facilitation of PLR. It is necessary to investigate ways in which society might appropriately discharge its obligation to facilitate valuable PLR activities. Some possibilities worth exploring include: the development of an online platform where PLR activities may be publicly registered; the provision of scientific advice on research proposals through publicly funded panels of experts, operating at an international level; online tools, including scientific and ethical checklists of relevant considerations; and, the development of journal appraisal systems that are known to be receptive to submissions of results from PLR. Those engaged in PLR, along with other stakeholders, should contribute to an ongoing dialogue about possible means of social facilitation.

\section{NEXT STEPS: A RESEARCH AGENDA}

The potential benefits and pitfalls of PLR demand further interdisciplinary inquiry. A vital starting point will be empirical investigations to map the various forms of existing PLR activity, their prevalence and distribution; to understand the objectives of those engaged in it; to explore their experiences, including how they address the ethical challenges; and to identify their perspectives on how PLR may best be facilitated. On the basis of these empirical findings, further research activity should be conducted on normative questions surrounding PLR. These questions include the bearing of existing legal and institutional norms, and how they might be revised or supplemented in order to foster PLR activity. More fundamentally, they also include the underlying values that PLR activity serves, such as the individual right to scientific and cultural participation and the common good of a more participatory scientific culture.

In forging the new social contract on health research, we need seriously to consider the scope and content of its terms. Key among those terms must be a set of mutual responsibilities that facilitates the realisation of PLR's full potential as an innovative form of research in which we are all stakeholders.

\section{Author affiliations \\ ${ }^{1}$ Institute of Biomedical Ethics, University of Zurich, Zurich, Switzerland \\ ${ }^{2}$ Dickson Poon School of Law, King's College London, London, UK \\ ${ }^{3}$ Centre for Bioethics and RandD, UCL and UCLH, London, UK \\ ${ }^{4}$ Department for Applied Bioinformatics, Institute for Cell Biology and Neuroscience, Goethe University, Frankfurt am Main, Germany \\ ${ }^{5}$ Berman Institute of Bioethics, Johns Hopkins University, Baltimore, Maryland, USA ${ }^{6} \mathrm{BMJ}$, London, UK \\ ${ }^{7}$ UCL Laws, University College London, London, UK \\ ${ }^{8}$ Humanities and Social Sciences, Wellcome Trust, London, UK \\ ${ }^{9}$ Department of Philosophy, Cambridge University, Cambridge, UK \\ ${ }^{10}$ Centre for Family Research, University of Cambridge, London, UK \\ ${ }^{11}$ Department of Social Science, Health \& Medicine, King's College London, London, UK \\ ${ }^{12}$ University of Oxford, The Ethox Centre, Oxford, UK \\ ${ }^{13}$ PatientsLikeMe, Boston, USA \\ ${ }^{14}$ Yeoh Tiong Lay Centre for Politics, Philosophy and Law, Dickson Poon School of Law, King's College London, London, UK}

Correction notice This article has been corrected since it was published Online First. The spelling of author name 'Navjyot Ladher' has been corrected to 'Navjoyt Ladher'.

Twitter Follow Effy Vayena at @EffyVayena, Jonathan Montgomery at @Prof_JonMont and John Tasioulas at @JTasioulas

Contributors This article is a result of discussions that took place during the workshop "Towards developing best practice for ethical participant-led health research" held at UCL, 9-10 May 2014. The workshop was funded by the Wellcome Trust and the UCL Grand Challenges fund. All listed authors actively participated in the above workshop, contributed to the discussions and helped develop the concept of this article. EV, JT and RB developed the first draft of this article, which reflects the consensus points that emerged in discussion. The draft was circulated to all other participants (SJE, BG, JPK, NL, JM, DO, OO, MS, MPR and PW) who sent comments, revisions and editorial suggestions. $\mathrm{EV}$, JT and RB produced another version incorporating these suggestions. The submitted version was approved by all authors. EV, JT and RB are the guarantors of the article. 
Competing interests PW is an employee of PatientsLikeMe and holds stock/ options in the company. The PatientsLikeMe R\&D Team has received research funding (including conference support and consulting fees) from Abbvie, Accorda, AstraZeneca, Avanir, Biogen, Boehringer Ingelheim, Genzyme, Janssen, Johnson \& Johnson, Merck, Novartis, Sanofi, and UCB. The PatientsLikeMe R\&D team has received research grant funding from Kaiser Permanente, the Robert Wood Johnson Foundation, Sage Bionetworks, The AKU Society, University of Maryland, and University of Michigan. BG is a cofounder of openSNP.com, a not-for-profit PLR project registered under a creative commons zero license. NL is employed by the $B M J$ as a clinical editor. JM is Chair of the Health Research Authority, although contributing to this article in a personal capacity. DO is an employee of the Wellcome Trust, although contributing to this article in an independent capacity. His views do not necessarily represent those of the Wellcome Trust. 00 is Chair of the Medical Research Council's Ethics, Regulation and Public Interest Committee, although contributing to this article in a personal capacity.

Provenance and peer review Not commissioned; externally peer reviewed.

Open Access This is an Open Access article distributed in accordance with the Creative Commons Attribution Non Commercial (CC BY-NC 4.0) license, which permits others to distribute, remix, adapt, build upon this work non-commercially, and license their derivative works on different terms, provided the original work is properly cited and the use is non-commercial. See: http://creativecommons.org/ licenses/by-nc/4.0/

\section{REFERENCES}

1 Desmond-Hellmann S. Toward precision medicine: a new social contract? Sci Trans/ Med 2012;4:129ed3.

2 NHS citizens. http://www.involve.org.uk/blog/2014/04/28/ nhs-england-citizens-assembly/

3 Godlee F. Towards the patient revolution. BMJ 2014;348:g1209.

4 Vayena E, Tasioulas J. The ethics of participant-led biomedical research. Nat Biotechnol 2013;31(9):786-7.
5 Frost JH, Massagli MP, Wicks P, et al. How the social web supports patient experimentation with a new therapy: the demand for patient-controlled and patient-centered informatics. AMIA Annu Symp Proc 2008;2008:217-21.

6 Wicks P, Vaughan TE, Massagli MP, et al. Accelerated clinical discovery using self-reported patient data collected online and a patient-matching algorithm. Nat Biotechnol 2011;29(5):411-14.

7 Dockser Marcus A. Trials. A Wall Street Journal special project. 2014. http://projects wsj.com/trials/\#chapter $=1$

8 National Institutes of Health. National Center for Advancing Translational Sciences. http://www.ncats.nih.gov/news-and-events/features/npc1-trial.html

9 Greshake B, Bayer PE, Rausch H, et al. openSNP--a crowdsourced web resource for personal genomics. PLOS ONE 2014;9:e89204.

10 Swan M. Crowdsourced health research studies: an important emerging complement to clinical trials in the public health research ecosystem. J Med Internet Res 2012;14(2):e46.

11 The Universal Declaration of Human Rights. Article 27. http://www.un.org/en/ documents/udhr/

12 International Covenant on Economic, Social and Cultural Rights. Article 15. http:// www.ohchr.org/EN/Professionallnterest/Pages/CESCR.aspx

13 Wicks P, Vaughan T, Heywood J. Subjects no more: what happens when trial participants realize they hold the power? BMJ 2014;348:g368.

14 Chio A, Mora G. The final chapter in the ALS lithium saga. Lancet Neurol 2013;12 (4):324-5.

15 Wicks P, Heywood, J, Vaughan T. 2012 Waiting for $p<0.05$. figshare.

16 Vayena $E$. The next step in the patient revolution: patients initiating and leading research. BMJ 2014;349:g4318.

17 Vayena E, Tasioulas J. Adapting standards: ethical oversight of participant-led health research. PLoS Med 2013;10:e1001402.

18 Vayena $E$, Mastroianni A, Kahn J. Ethical issues in health research with novel online sources. Am J Public Health 2012;102(12):2225-30.

19 O'Connor D. The apomediated world: regulating research when social media has changed research. J Law Med Ethics 2013;41(2):470-83.

20 Vayena $E$, Mastroianni A, Kahn J. Caught in the web: informed consent for online health research. Sci Transl Med 2013;5:173fs6. 